\title{
The Value of Osteopathy for Children. The Great Contribution of Dr. Viola Frymann, Piooner in Pediatric Osteopathy
}

\author{
Stefano Bonomi ${ }^{1,2 *}$ and Monica Filisetti ${ }^{1,2}$ \\ ${ }^{1}$ Osteopathic Center for Children Italy (Lonato del Garda, Bs), Italy \\ ${ }^{2}$ Desenzano del Garda Hospital (ASST del Garda, Bs), Italy \\ *Corresponding Author: Stefano Bonomi, Osteopathic Center for Children Italy \\ (Lonato del Garda, Bs) and Desenzano del Garda Hospital (ASST del Garda, Bs), \\ Italy. E-mail: bonomistefano@libero.it
}

Received: July 09, 2020

Published: August 24, 2020

(C) All rights are reserved by Stefano

Bonomi and Monica Filisetti.

\begin{abstract}
Osteopathy medicine is expanding in an integrated medicine perspective.

Dr. Viola Frymann is an osteopathic physician who dedicated her life to the study and application of osteopathy for children. She founded the Osteopathic Center for Children in San Diego (California), and she is still recognized as an international reference point for pediatric osteopathy. A review of her work and of her scientific research shows the value of osteopathy in many areas of pediatric health care: neonatal problems, postural disorders, support to child's development with regard to the neurological, learning and visual aspects.
\end{abstract}

Keywords: Osteopathy; Osteopathic Medicine; Physician

\section{Introduction}

Osteopathic medicine is a manual therapy based on gentle manipulations of the musculoskeletal system. Scientific basis of osteopathy is the accurate knowledge of anatomy, physiology and neurophysiology of the human body.

The founder of osteopathic medicine is Andrew Taylor Still (1828 - 1917), a physician who practiced in North America (Kansas and Missouri) [1]. The original American School of Osteopathy was founded in 1892 in Kirksville (Missouri) where one of the most important Universities of Medicine and Osteopathy is still existing (A.T. Still Osteopathic Medical University). The teachings and practice of osteopathy are expanding worldwide.

William Garner Sutherland (1873 - 1954), a student of Dr. Still, expanded the osteopathic principles to the cranial field and fo- cused his attention on the relationship between cranio-vertebral structures and the functioning of the nervous system [2].

The science of osteopathy is based on the following principles:

- $\quad$ Structure and function are related. The structure of the body is intimately related to the function. The primary function is the motion, fundamental to all other functions of the various tissues and body organs. The freedom of the inherent physiological motion of the musculoskeletal system supports the efficient functioning of all other body systems, especially of the nervous system.

- The whole body is a dynamic unit of functions; each body part depends on each other. The osteopathic approach looks at the whole patient, the whole body needs to be integrated. 
The body has in itself an inherent therapeutic capacity and a constant drive towards health. Physiological mechanisms of selfregulation and neural compensations are an example of this body power [1,3-6].

The principles of osteopathy are more comprehensible if applied to babies. Altough Dr. Still and Dr. Sutherland described their experience with children, the real pioneer of pediatric osteopathy is Dr. Viola M. Frymann, student of Dr. Sutherland.

Dr. Viola Frymann (1921-2016) dedicated her life to treat children and to study the scientific basis of osteopathy. She shared her experience with many scientific communities around the world. In 1982 she founded the "Osteopathic Center for Children" in San Diego (California). The Center is dedicated to families with children coming from all over the world, especially children afflicted with neurological problems. According to the teachings and the model of Dr. Viola Frymann, pediatric osteopathy requires specific skills and training to develop a particular sense of touch.

The osteopathic evaluation includes the examination of posture, motor skills together with a specific examination of the musculoscheletal system. Osteopaths have to be skilled at examining the soft tissues of the baby, at recognizing tissue texture abnormality, asymmetry and motion restriction. A gentle perceptive palpation can detect somatic dysfunction. Somatic dysfunction, listed in the International Classification of Diseases (ICD-10 Segmental and Somatic Dysfunction), is a restriction of movement in a part of the musculoskeletal system [7].

During the evaluation, every part of the body is controlled: vertebral column, thoracic area, pelvis and sacrum, lower and upper extremities, joints. The evaluation of the head area considers sthe skull as a whole. The skull is made up of some twenty-six bones. In newborns, some of these bones are separated into several parts. During the evaluation of the head, the fingers check the various joint between the bones in the head to find out if there is any overriding of any suture or any hardness or irregularity, if one bone is pushed up against the other and even if there is any asymmetry of the head, any imbalance in the structure of the head bones [4].

Manipulative treatments consist in very delicate manipulations and soft mobilizations of the musculoskeletal structures. The purpose of the treatment program is the restoration of unrestricted, symmetric, physiologic mobility of all body parts, aimed at improv- ing postural setting and at enabling free and symmetrical movement.

Every child needs a specific program of osteopathic treatment, which may be integrated with other treatments, if indicated $[8,9]$. Osteopathic manipulative treatment appears to be a safe treatment modality in the pediatric population when administered by physicians skilled in pediatric osteopathy [10].

\section{Aim}

Aim of that paper is consider which conditions could benefit from osteopathic approach, according to the long-life experience of Dr. Viola Frymann. Moreover the aim is to explore how common disorders in children could be view in the light of the osteopathic concept.

This research is intended to help pediatricians and osteopaths who want to explore the potential of osteopathy for children.

\section{Methods}

We review the work of Dr. Frymann to explore her experience and scientific work.

The sources for our research are some articles published in scientific journals or collected in the book "The collected papers of Viola Frymann. The legacy of osteopathy to children", edited by the America Academy of Osteopathy in 1998. Other sources come from the teachings provided during the courses of Pediatric Osteopathy, done at the Osteopathic Center for Children in the period 20112015. In these years the authors of the article have followed a training in pediatric osteopathy at the Osteopathic Center for Children.

We only consider papers in which children are taken into account.

In the results we describe clinical conditions taken into consideration in scientific articles. For some conditions we present research projects developed at the Osteopathic Center for Children by Dr. Frymann with the collaboration of other professionists. For other conditions we report scientific background and principles of osteopathic approach, as described in the article of Dr. Frymann.

In the discussion we try to summarize the potential of osteopathy for children and to outline possible further applications and directions for research. 


\section{Results and Discussion}

\section{Common problems of newborns}

From an osteopathic point of view the process of birth is one of the most significative experience.

The brain is contained within the bony skull, which at the time of birth is designed to accept the temporary compression of the birth canal, and expand fully when the baby cries immediately after birth. The lower end of the central nervous system is located within the sacrum, the large bone forming the back of the pelvis. This is also designed to adsorb the compressing forces of the contracting uterus, and then to be restored by bodily movements after birth. The vertebral column protects the spinal cord connecting the head and the pelvis. The mechanism of labor is considered as a possible influence on the craniosacral mechanism. Problems of labor or delivery may compromise these structural areas and thus disturb the nervous system within, interfering with its physiological development [4].

The area of the baby's head that leads the way out of the birth is the occipital area. If there is a difficult birth such as in case of delay in delivery, vacuum extraction, presentation of baby in uncorrect position or some problems such as cord around the baby's neck, the occipital area suffers that impact. If there is a degree of compression within the baby's head, this may cause an irritation of some important nerves that come out of the base of the skull. The hypoglossal nerve (the $12^{\text {th }}$ nerve) is reponsible for the activity of the tongue and therefore is important in the sucking process. The vagus nerve /the 10th cranial nerve) passes out through the skull to the digestive tract, that is very much concerned with the activity of the digestive tract. Within the occiput there is also that large opening through which the whole brain stem becomes the spinal cord. All of nerve pathways that go to every structure in the body below the base of the skull must pass out through that hole in the occiput.

Signs of potential difficulty to adapt after a difficult delivery are delay in sucking, difficult learning to suck, vomiting or spitting up after feeding, asymmetrical motion of arms or legs, postural disorders, arched back or throwing head back when held on mother's shoulder or lying on the side, restlessness or inconsolable crying, troubles in sleeping, and finally during the growth lack of sequence or missing stages in motor development [11].
A study of 1250 newborns explore the possibility of a relation between the symptomatology in newborn infants and anatomicphysiologic disturbances of the craniosacral mechanism.

In the study was demonstrated that 139 babies (12\%) are healthy and have a free movable cranial mechanism. In other words all the bones of the head are in a correct relationship and move as they should. 368 newborns (30\%) have a gross, visible disturbance in the cranial mechanism ( as a cranial deformity and strain patterns within the development parts of the cranial bones), and show some symptoms of irritation in the central nervous system, circulatory system or breathing difficulty (vomiting, hyperactive peristalsis, tremor, hypertonicity, irritability). This result suggests a relationship between specific anatomic-physiologic distrurbances of the craniosacral mechanism and symptomatology in newborns. The remaining 729 newborns (58\%) are asymptomatic but the osteopathic evaluation detected structural strain patterns in the cranial mechanism. They may not be presenting major clinical problems at this age, but they can develop some problems during the growth. The possibile etiologic significance of the strain patterns in asymptomatic newborns recommends further studyies.

Structural dysfunctions resulting from birth trauma can be detected and corrected early, in order to establish or restore optimal anatomic-physiologic integrity, so that neurological development progresses satisfactorily.

The cranium of a newborn infant is a very delicate structure, and the approach to it must be extremely gentle and respectful. The art of palpation requires to develop a perceptive and understanding sense of touch in the fingers [4].

Provide an osteopathic evaluation and treatment of the baby during the newborn period is the essence of prevention [12].

\section{Respiratory problems}

The osteopathic approach for children includes many techniques aimed at the respiratory system and immune system in children.

\section{Allergy and asthma}

Allergy is a state of hypersensitivity of the patient as a whole, which may manifest in a particular area of the body, with different clinical manifestations (rhinitis, conjunctivitis, asthma, eczema...). 
From an osteopathic point of view this suggests that an autonomic imbalance has occurred and the symphatetic partner has withdrawn its part of the autonomic duet. The allergy is recognized as a dysfunction of the whole man in relation to his whole environment.

The management of children with allergies and asthma includes diet, environmental measures, osteopathic treatment of structural problems within the whole body and medications when necessary.

Allergic hypersensivity and the response to stress are related phenomena. There is a reciprocal relation between pituitary and adrenal glands and thymus. During osteopathic evaluation and treatment, the focus is directed on the total patient, to the structural integration of the musculoskeletal system from the head to the feet, so to apply techniques which will normalize the function of these respective glandes. In particular we must examine the area of the symphathetic outflow, the ribs and the thoracic portion of the spine and its related soft tissue, the diaphragm, its motility, its attachments and its remote relation with the pelvic and cranial diaphragm, the cranial base, particularly the motility of the sphenoid bone and the sella turcica, which enclose the pituitary gland, the anterior cervical and mediastinal fasciae, the local areas of allergic manifestations, such as the nasal and facial bones in allergic rhinitis and sinusitis $[13,14]$.

\section{Respiratory infections}

We consider children who present recurrent ear infections continuing over a period of years. A comprehensive diagnosis of the child who suffer from recurrent otitis requires the examination of the musculoskeletal system and its integration with the mechanism of the cranium. nadequate drainage from the eustachian tubes maintains congestion and hypertrophy of tonsils and adenoids. Efficient drainage from the ear (lymphatic, venous and the drainage of the mucus from the estachian tube) depends on the anatomical-physiological integrity of the anatomical structures to which it is connected: temporal bone and facial bones, cervical spine with its various fascial planes, superior thoracic outlet, the clavi-pectoral fascia and the thoracic diaphragm.

The restoration of the uninhibited, symmetric, physiological and intrinsic motion by the use of a gentle and perceptive osteopathic manipulative treatment, if specifically administered, is the first step in the therapeutic program. In addition to this, it's also important to improve venous and lymphatic drainage. This is supported by an adequate nutrition. This program will not immediately transform a recurring sick child into a healthy one. It will turn the situation around, so that these events will become less frequent and less intense, the general well-being will improve and the susceptibility will be overcome [15].

\section{Postural disorders}

The posture establishes a frame of reference for visual space in which the child moves, while performing visually centered tasks. Any interference, adaptation, or stress which limits his movement is significant. Limitations of movement prevent a child from moving to optimal postural homeostasis [16].

The osteopath looks at the posture and the movement and works to allow for a harmonious body position and free movement in every part of the musculoskeletal system, considering specific characteristics in different period of childhood.

\section{Positional plagiocephaly}

In newborns the most frequent postural problem is positional plagiocephaly, considered as a visible deformation of the head shape in the occipital area, as a consequence of an asymmetrical position of the head. Visual examination of the newborn may reveal a visible deformity, with a prominence or pointedeness of the interparietal occiput and a flat sopraocciput. The disturbance is not confined to the occiput but disturbs all cranial mechanism as a whole. This condition could impact motor function and child development. Plagiocephaly is considered as a condition accessible to palpatory diagnosis and responsive to osteopathic treatment. It's the structural dimension of the structure/function relationship [3].

\section{Scoliosis}

A paper of Dr. Frymann describes the osteopathic approach to scoliosis. Structural causes of scoliosis are rare. Much more common are adolescent idiopathic functional spinal curvature. "idiopathic" means that the cause is unknown, "adolescent" implies that it is most commonly found as the child enters adolescence or teenage years, and fuctional indicate that there is no bony deformities. However, there are some causative factors recognized by the osteopathic physician, that are responsive to osteopathic manipulative treatment. In order to evaluate them, he regards this patient as a dynamic unit of function from head to feet and not merely as a vertebral column with an unusual curve in it. Examining the 
standing patient shape, the back, the level of ears, the shoulders, the scapulae or shoulder blades, the crests of the ilia are noted for their symmetry. If the patient then bends one knee but keeps the weight equally on two feet, it is possible to observe a side-bending in the lumbar area. Next, ask the patient to balance on one leg and note how far the pelvis descends on the opposite side. See to what extent the patient can bend forward, by touching his toes, without bending the knees. As the patient uncurls note whether the rib cage is symmetrical on both sides.

The patient is then examined lying on the back, to evaluate leg length asymmetry, pelvic balance, symmetrical motion of the sacrum within it and to evaluate the spinal muscles for symmetrical tension or vertebral rotation. The cranial mechanism is then palpated for distortion of position or asymmetry of motion. The question might be: what does the head have to do with a spinal curvature? From a functional point of view, the body hangs from the head and distortion of the cranial mechanism predisposes to curvature in the spine by means of unequal fascial drags on the body. The diagnosis will also include a standing X-rays.

The treatment will include osteopathic manipulative treatment to the pelvis and the head, the rib cage, the abdominal wall and the fascial mechanism of the body as well as the area manifesting the spinal curve. In addition, some exercises may be given. Other treatments may be indicated in severe structural scoliosis or if the condition has rapidly deteriorated [17].

\section{Visual disorders}

The basis to understand the value of osteopathy in children with visual disorders is always anatomy. The eye is a neurovascuolar-fibrous globe connected to the brain from which it takes origin by a stalk consisting of optic nerve interpenetrated by ophtalmic artery. The seven bones which enter the formation of the orbit are so ingeniously related to determine the size and shape of this cavity. Moreover, by their extrinsic relationship, these bones connect the orbit with all the other cranial bones of the head. It is therefore conceivable that the conditions of myopia, hypermetropia, astigmatism, and heterophoria may be influenced by any treatment that is able to affect the bony structure of the head. Measured improvement has been recorded in many cases $[16,18]$.

Dr. Frymann used to collaborate with Dr. Amorita Treganza and Dr. Claude Valenti, behavioral optometrist, specialized in vision therapy for children.
Consider posture and motor pattern of developing body is integral part of modern vision therapy. Learning is based on movement. A child arrives in this world already equipped with the machinery of movement. He uses these action systems when he teaches himself to reach-grasp-manipulate-release, to crawl, to creep, to stand. In all these activities, he uses his eyes to steer himself through space. He then learns to use his body parts, hands and eyes for special movement.

Limitations of movement prevent a child from moving to optimal postural homeostasis and could create problems in visually centered learning. There are many unanswered questions relative to cause and effect in learning problems, behavioral problems and physio-psycological development of the child. Our experience supports the benefits of the collaboration between osteopathy and behavioral otpometry, to support child development and prevent learning problems [16].

\section{Learning problems}

A research published in 1976 concerns the experience of more than 100 children with learning difficulties, followed at the Osteopathic Center for Children. The history of children was studied about pregnancy, birth, early development, childhood behavior, history of trauma or illnesses. The evaluation included the examination of all body postures and movements (gross and fine motor, coordination, ocular function), evaluation of the whole musculoskeletal system and cranial mechanism.

The observation revealed that most of these children had a difficult birth history or suffered from some head trauma in the first 2 years. Moreover, in a high percentage of children, an accurate osteopathic evaluation showed the presence of strain patterns in the craniosacral mechanism. These observations suggest some consideration about the origin of learning process and learning disorders.

In the article there is a detailed description of anatomic structures involved in the process of learning with particular attention to the visual system.

The process of reading involves recognition, interpretation, recollection, and comprehension of a sequence of complex configuration, made possible by a smooth movement of both eyes from left to right along a line of print and the transmission of the impulses through the pathways described to the interpretative areas of the cerebrum, relating them to other impressions stored within the 
memory and delivering them to consciousness as information requiring action. Nerve pathways concerned with perception are complex and involve many connections with interrelated functions, built in a precise geometric pattern. For example, the axes of the orbit intersect above the postrior boundary of the sella turcica and may be projected into the controlateral posterior cranial fossa above the tentorium cerebelli. In this complex systems the connections involve many neurological structures; few of these have been established at the time of birth, in the largest part experience creates functional patterns that mold developing structure.

The hypothesis derived from clinical and anatomical observation is that the developing nerve pathways are established within these geometric forms. If these forms are distorted prior to completion of development of these nerve pathways, these last can develop distortion, thus creating confusion in sensory input and causing poor coordination in motor activity. The study has demonstrated that there is a critical period of susceptibility when strain patterns contribute to the learning problems, and that this critical period, up to 2 years of life, is the period of opportunity for the optimum benefit $[19,20]$.

\section{Neurological problems}

A research project conducted at the Osteopathic Center for Children (San Diego) between 1986 an 1989 in cooperation with Dr. Peter Springall, neurologist, was published in 1992. The aim was to evaluate the outcome of the osteopathic treatment of 186 children with neurologic development problems.

Six to twelve osteopathic treatments were given at 1-week intervals. The objective of treatment was the restoration of unrestricted, symmetric, physiologic inherent mobility in all parts of the body. The individual treatment was tailored to the needs of each child. During treatment, interesting toys held attention and live classical piano music accompained all treatments. The choice of music is customized for each treatment.

The Houle's Profile of Development was used to evaluate the child's development status before, during and after the osteopathic treatmente program. The profile included three measures of sensory performance (visual, auditory and tactile competence) and three of motor competence (manual competence, mobility and spoken language).
Significant progress in response to the program care was demonstrated. Neurologic performance significantly improved after treatment and benefits continued after several months' interval. The results supports the use of osteopathic manipulative treatment as a part of pediatric health care based on osteopathic medical philosophy and principles [21].

\section{Orthodontic problems}

The orhodontist is concerned with restoring precise, efficient anatomic-physiologic relationship between the teeth. He recognizes under-development, over-development or distorted development of one or both jaws. He uses mechanical appliances to correct the development problems and to produce correct occlusion. His osseus concerns may include techiques to widen the palatal arch by expanding the intermaxillary suture.

It is not an uncommun phenomenon, after years of excellent orthodontic treatment with precise appliances and very carefully monitored adjustments, to see that the occlusion gradually regresses.

Osteopath considers the anatomic-physiologic basis of the correlation between the teeth, cranial bones and posture. If there is a free physiological motion within the total mechanism before the orthodontist begins his work, now he will only have to encourage the bones and the teeth to grow in the anatomic relationships which they are now ready to accept. He will not have to force them against rigid resistance. The whole orthodontic program will be easier, less uncomfortable and of shorter duration [22,23].

\section{Prevention}

Prevention is an important aspect of osteopathic practice.

The sooner the child can be treated the sooner the optimal motion can be established on the body.

The skull is a mold in which nervous structure and function develop. Therefore optimal structural and functional integrity of the head allows optimal development and function of the central nervous system. If the osteopathic physician can evaluate and, if necessary, correct the structure of the baby as soon as possible after birth, many of the problems of childhood may be avoided. This is the best prevention. 
Osteopathic manipulation as a therapeutic measure have best prognosis if applied in the early years of childhood. In any case older children can also be helped to attain their maximum potentia $[4,20,21,24]$.

"Osteopathy applied to the newborn is one of the most significant contributions to preventive medicine today. The normalization of the structural and functional mechanism in the neonatal period allows the individual to take a long step forward on the road to the maximum functional efficiency of which he will be capable" [5].

\section{Considerations/Conclusion}

Dr. Frymann was a pioneer of pediatric osteopathy. She dedicated her life, with devotion and professionalims, to discovering the area of application of the osteopathic approach to support child health and development. Some considerations form her work and teachings.

The experience of Dr. Frymann offers a new model of care for children, that consider each baby as unique creature. The inspired view of Dr. Frymann considers the fondamental relationship between muscular-scheletal mobility and neural development. Osteopathic approach is customized and considers the child and the environment where he lives. The aim is to create the best condition for the child to enter in relation with the environment [25]. Moreover, osteopathy frequently cooperate with other health professionals, such as neurologists, development optometrists, ortodontists, in a multidisciplinary and integrate perspective $[26,27]$. Looking at the whole child with all his interrelated and interdependent parts requires a team. The challenge of Dr. Frymann is to understand how osteopathic approach could help children to develop their best potential. Dr. Frymann's effort is to study the cause of common disorder in newborns and children, that can impact their lives. Many of clinical conditions described and studied by Dr. Frymann are the most common conditions for osteopathic consultation in many countries nowadays Recent literature confirms that many disorders in newborns and children benefit from osteopathic treatment. For example postural disorders, plagiocephly, torticollis [28-33].

Thanks to our experience, owing to a long period of training in pediatric osteopathy at the Osteopathic Center for Children, we introduce the osteopathic approach in a Health Public Hospital in
Italy. In 2010 the Service "Pediatric Osteopathy and Neurodeveolpmental follow up" was established. The Service offers a program of early intervention, based on the osteopathic integrated approach that is dedicated to newborns at risk due to developmental delay (prematurity, dystocic delivery, neurological or congenital syndromes, postural defects). The ostepathic treatment is integrated with a home program that involves the parents and caregivers to support child develolpment. In 10 year-experience the Service took care of more than 600 babies, followed for at least the first year of life and resuts are satisfactory [34,35].

Dr. Frymann had insights that they anticipated some discovery of recent neuroscience. She spoke about neural plasticity and the importance of early intervention also involving the parents, in addition to the correlation between the head case and central nervous system. She suggested the value of osteopathic intervention based on that principles that are well recognized and demonstrated nowadays [36-40].

The work of Dr. Frymann opens the doors to the scientific community in order to deepen osteopathic knowledge in the light of new neurosciences discoveries.

Pediatric osteopaths have the responsibility to make every attempt to continue her work and research so to consider the potential of osteopathy and elaborate individualized integrated program of children care.

\section{Acknowledgments}

- The authors wish to express their gratitude to Dr. Viola Frymann.

- They appreciate her serious professionalism, generosity and profound humanity.

- They thank all the people who collaborated with Dr. Frymann at the Osteopathic Center for Children in San Diego, especially Mrs. Sharon Lee Master, Mrs. Anna Marshall and Dr. Claude Valenti. 


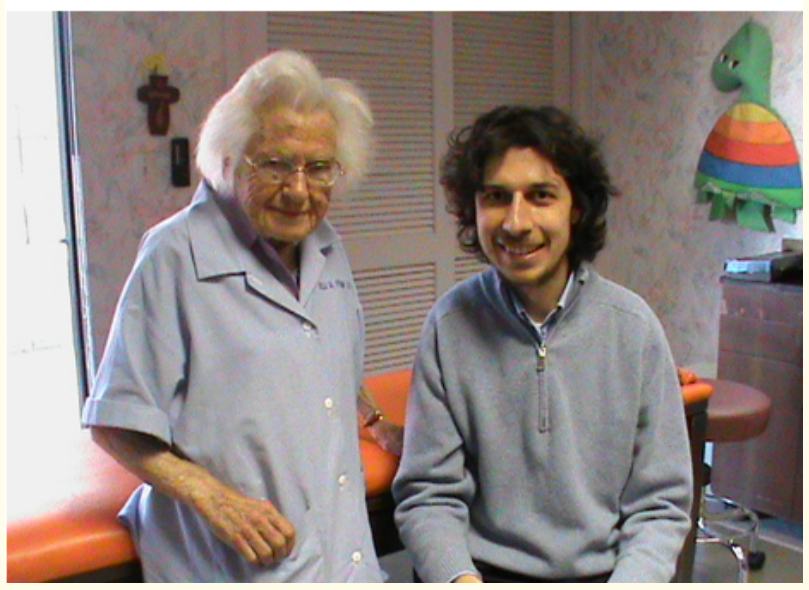

Figure 1: Dr. Viola Frymann and Dr. Stefano Bonomi at the Osteopathic Center for Children (San Diego).

\section{Bibliography}

1. Still AT. "The philosophy and mechanical principles of Osteopahy". Kirksville, Missouri (USA) (1892).

2. Sutherland WG. "Teachings in the science of osteopathy". SCT Foundation Editor. Texas (1990).

3. Frymann VM. "Cerebral Dysfunction: prevention and treatment in the light of the osteopathic concept". The collected papers of Viola M. Frymann. Legacy of Osteopathy to Children. American Academy of Osteopathy. Indianapolis (1998).

4. Frymann VM. "Relation of disturbances of craniosacral mechanisms to symptomatology of the newborn: study of 1,250 infants". The Journal of the American Osteopathic Association 65.10 (1966): 1059-1075.

5. Frymann VM. "The expanding osteopathic concept". AAO Yearbook. 67 (1967): 50-62.

6. Sutherland WG. "Contribution of Thought". Edited by Sutherland AS, Wales AL. Sutherland Cranial Teaching Foundation Ed. (1967).

7. ICD-10. International statistic classification of diseases and related Health Problems. WHO version, (2016).
8. Frymann VM. "What is osteopathic Manipulation?" Courses of Pediatric Osteopathy, Osteopahic Center for Children, San Diego. 2011-2015.

9. Frymann VM. "Cerebral dysfunction: prevention and treatment in the light of the osteopathic concept". Osteopathic Medical News 4.9 (1987).

10. Hayes NM and Bezilla TA. "Incidence of iatrogenesis associated with osteopathic manipulative treatment of pediatric patients". The Journal of the American Osteopathic Association 106.10 (2006): 605-608.

11. Frymann VM. “Common problems of Newborn”. Courses of Pediatric Osteopathy, Osteopahic Center for Children, San Diego. 2011-2015.

12. Frymann VM. "Birth trauma: the most common cause of developmental delays". Courses of Pediatric Osteopathy, Osteopahic Center for Children, San Diego. 2011-2015

13. Frymann VM. "The osteopathic approach to the allergic patient". The collected papers of Viola M. Frymann. Legacy of Osteopathy to Children. American Academy of Osteopathy. Indianapolis (1998).

14. Frymann VM. "The core link and the three diaphragms". The collected papers of Viola M. Frymann. Legacy of Osteopathy to Children. American Academy of Osteopathy. Indianapolis (1998).

15. Frymann VM. "Diagnosis and treatment of otitis media in children". The collected papers of Viola M. Frymann. Legacy of Osteopathy to Children. American Academy of Osteopathy. Indianapolis (1998).

16. Frymann VM and Treganza A. "Explorations into posture and body mechanics". The collected papers of Viola M. Frymann. Legacy of Osteopathy to Children. American Academy of Osteopathy. Indianapolis, (1998).

17. Frymann VM. "The osteopathic approach to the child with scoliosis". Courses of pediatric osteopathy, osteopahic center for children, san diego. 2011-2015

18. Frymann VM. "The expanding osteopathic concept". The collected papers of Viola M. Frymann. Legacy of osteopathy to 
children. American academy of osteopathy. Indianapolis (1998).

19. Frymann VM. "Learning disabilities in childhood". The collected papers of viola m. Frymann. Legacy of osteopathy to children. American academy of osteopathy. Indianapolis (1998).

20. Frymann VM. "Learning difficulties of children viewed on the light of the osteopathic concept". The Journal of the American Osteopathic Association 76.1 (1979): 46-61.

21. Frymann VM., et al. "Effect of osteopathic medical management on neurologic development in children". The Journal of the American Osteopathic Association 92.6 (1992): 729-744.

22. Frymann VM. "Why does the orthodontist need osteopathy in the cranial field?" The collected papers of Viola M. Frymann. Legacy of osteopathy to children. American academy of osteopathy. Indianapolis, 1998

23. Frymann VM. "Cranial osteopathy and its role in disorders of the temporomandibular joint". The collected papers of Viola M. Frymann. Legacy of osteopathy to children. American academy of osteopathy. Indianapolis (1998).

24. Frymann VM. "What's in a name?" The Journal of the American Osteopathic Association 99.11 (1999): 557.

25. Frymann VM. Steps you can take at home. The collected papers of viola m. Frymann. Legacy of osteopathy to children. American academy of osteopathy. Indianapolis (1998).

26. Morin C., et al. "Descriptive study of interprofessional collaboration between physicians and osteopaths for the pediatric population in Quebec, Canada". BMC Health Services Research 17.1 (2017): 726.

27. Wainapel SF., et al. "Integrating complementary/alternative medicine into primary care: evaluating the evidence and appropriate implementation". International Journal of General Medicine 8 (2015): 361-372.

28. Filisetti M., et al. "Osteopathy in childhood. Principles and clinical applications". Rivista Italiana di Pediatria Ospedaliera 5.1 (2018).
29. Amiel-Tison $\mathrm{C}$ and Soyez-Papiernik E. "Cranial osteopathy as a complementary treatment of postural plagiocephaly". Archives of Pediatrics 15 (2008): S24-30.

30. Lessard S., et al. "Exploring the impact of osteopathic treatment on cranial asymmetries associated with nonsynostotic plagiocephaly in infants". Complementary Therapies in Clinical Practice 17.4 (2011): 193-198.

31. Sergueef N., et al. "Palpatory diagnosis of plagiocephaly". Complementary Therapies in Clinical Practice 12.2 (2006): 101110.

32. Mills MV. "Consider osteopathic manipulation in next positional plagiocephaly research". Journal of Pediatrics 148.5 (2006): 706-707.

33. Snider KT., et al. "Retrospective medical record review of an osteopathic manipulative medicine hospital consultation service". The Journal of the American Osteopathic Association 113.10 (2013): 754-767.

34. Filisetti M., et al. "A new model of early intervention based on the osteopathic integrated approach: clinical experience about 530 newborn". Journal of Pediatrics and Neonatal Care 5 (2019): 154.

35. Filisetti M., et al. "Positional plagiocephaly from structure to function: Clinical experience of the service of Pediatric Osteopathy in Italy". Early Human Development 146 (2020) 105028.

36. Hadders-Algra M. "Early human motor development: From variation to the ability to vary and adapt". Neuroscience and Biobehavioral Reviews 90 (2015): 411-427.

37. Cioni G., et al. "Early intervention in neurodevelopmental disorders: underlying neural mechanisms". Developmental Medicine and Child Neurology 58 (2016): 61-66.

38. Benzies KM., et al. "Key components of early intervention programs for preterm infants and their parents: a systematic review and meta-analysis". BMC Pregnancy Childbirth 13 (2013): S10.

39. Johnston MV. "Plasticity in the developing brain: implications for rehabilitation". Developmental Disabilities Research Reviews 15.2 (2009): 94-101. 
40. Kolb B and Muhammad A. "Harnessing the power of neuroplasticity for intervention". Frontiers in Human Neuroscience 8 (2014): 377.

\section{Assets from publication with us}

- Prompt Acknowledgement after receiving the article

- Thorough Double blinded peer review

- Rapid Publication

- Issue of Publication Certificate

- High visibility of your Published work

Website: $\underline{w w w}$.actascientific.com/

Submit Article: www.actascientific.com/submission.php

Email us: editor@actascientific.com

Contact us: +919182824667 